\title{
ARTICLE Role of endocannabinoids in the hippocampus and amygdala in emotional memory and plasticity
}

\author{
Amir Segev ${ }^{1}$, Nachshon Korem ${ }^{1}$, Tomer Mizrachi Zer-Aviv ${ }^{1}$, Hila Abush ${ }^{1}$, Rachel Lange ${ }^{2}$, Garrett Sauber ${ }^{2}$, Cecilia J. Hillard ${ }^{2}$ and $^{2}$ \\ Irit Akirav (iD)
}

Posttraumatic stress disorder (PTSD) is characterized by the reexperiencing of a traumatic event and is associated with slower extinction of fear responses. Impaired extinction of fearful associations to trauma-related cues may interfere with treatment response, and extinction deficits may be premorbid risk factors for the development of PTSD. We examined the effects of exposure to a severe footshock followed by situational reminders (SRs) on extinction, plasticity, and endocannabinoid (eCB) content and activity in the hippocampal CA1 area and basolateral amygdala (BLA). We also examined whether enhancing eCB signaling before extinction, using the fatty acid amide hydrolase (FAAH) inhibitor URB597, could prevent the shock/SRs-induced effects on fear response and plasticity. URB597 administered systemically $(0.3 \mathrm{mg} / \mathrm{kg})$ or locally into the CA1 or BLA (0.1 $\mu \mathrm{g} / \mathrm{side})$ prior to extinction decreased fear retrieval and this effect persisted throughout extinction training and did not recuperate during spontaneous recovery. A low dose of the CB1 receptor antagonist AM251 (0.3 mg/kg i.p. or $0.01 \mu \mathrm{g} / 0.5 \mu \mathrm{l}$ intra-CA1 or intra-BLA) blocked these effects suggesting that the effects of URB597 were CB1 receptor-dependent. Exposure to shock and reminders induced behavioral metaplasticity with opposite effects on long-term potentiation (LTP) in the hippocampus (impairment) and the BLA (enhancement). URB597 was found to prevent the opposite shock/SR-induced metaplasticity in hippocampal and BLA-LTP. Exposure to shock and reminders might cause variation in endogenous cannabinoid levels that could affect fear-circuit function. Indeed, exposure to shock and SRs affected eCB content: increased 2-arachidonoyl-glycerol (2-AG) and N-arachidonylethanolamine (AEA) levels in the CA1, decreased serum and BLA AEA levels while shock exposure increased FAAH activity in the CA1 and BLA. FAAH inhibition before extinction abolished fear and modulated LTP in the hippocampus and amygdala, brain regions pertinent to emotional memory. The findings suggest that targeting the eCB system before extinction may be beneficial in fear memory attenuation and these effects may involve metaplasticity in the CA1 and BLA.

Neuropsychopharmacology (2018) 43:2017-2027; https://doi.org/10.1038/s41386-018-0135-4

\section{INTRODUCTION}

Impaired ability to extinguish fearful associations to traumarelated cues may interfere with treatment response and be a premorbid risk factor for the development of posttraumatic stress disorder (PTSD) [1].

The endocannabinoid $(\mathrm{eCB})$ system plays a key role in the modulation of cognitive and emotional responses and it has been suggested as a therapeutic target for the treatment of severe stress associated with PTSD [2-5]. The eCB system consists of cannabinoid receptors (CB1r and $\mathrm{CB} 2 \mathrm{r}$ ) and the eCBs $\mathrm{N}$ arachidonylethanolamine (AEA) and 2-arachidonoylglycerol (2AG). It also includes eCB synthesis and degradation enzymes, fatty acid amide hydrolase (FAAH) and monoacylglycerol lipase (MAGL) for AEA and 2-AG, respectively.

The amygdala and hippocampus are brain regions involved in fear and memory and are highly implicated in PTSD. We have recently shown that exposure to the shock and reminders model of PTSD had opposing effects on hippocampal- and amygdaladependent processes: hippocampal plasticity and spatial memory were impaired, whereas amygdala plasticity and conditioned taste aversion enhanced [6]. These opposing effects were prevented by administering the $\mathrm{CB} 1 / 2$ receptor agonist WIN55-212,2 (0.5 mg/kg, i.p.) and the fatty acid amide hydrolase (FAAH) inhibitor URB597 $(0.3 \mathrm{mg} / \mathrm{kg}$, i.p.) $2 \mathrm{~h}$ after shock exposure [6]. We found that cannabinoids administered in the aftermath of trauma can prevent the development of PTSD-like behaviors $[2,7]$.

However, cannabinoids administered in the aftermath of trauma exposure have a limited translational value. First, we cannot predict who will develop PTSD and intervention in the aftermath of trauma is given to all traumatized individuals. Second, many individuals may miss the opportunity to be treated in the first hours after the trauma. Hence in the current study, we aimed to examine whether administrating URB597 before extinction will attenuate fear and facilitate extinction in the BLA and CA1. We used URB597 as it was shown to have antianxiety and antidepressant-like effects in different models $[6,8,9]$. URB597 $(0.3 \mathrm{mg} / \mathrm{kg})$ prevents AEA inactivation by targeting the intracellular enzymatic activity of FAAH (inhibits FAAH activity with an ID50 value of $0.15 \mathrm{mg} \mathrm{kg}$ after systemic administration in the rat

\footnotetext{
${ }^{1}$ Department of Psychology, University of Haifa, Haifa 3498838, Israel and ${ }^{2}$ Department of Pharmacology and Toxicology, Neuroscience Research Center, Medical College of Wisconsin, Milwaukee 53226, USA

Correspondence: Irit Akirav (iakirav@psy.haifa.ac.il)

These authors contributed equally: Tomer Mizrachi Zer-Aviv, Nachshon Korem, Amir Segev.
}

Received: 7 March 2018 Revised: 19 June 2018 Accepted: 21 June 2018

Published online: 27 June 2018 
[10]). Moreover, URB597 was found to trigger active coping behavior [11], and to prevent the effects of exposure to shock and reminders in a rat model of PTSD on depressive- and anxiety-like behaviors [6, 12]. Intra-BLA URB597 facilitated extinction and attenuated startle response following shock and reminders [13], and decreased anxiety under conditions of low emotional arousal [14]. It has been suggested that this indirect agonist has the advantage that it is more selective than direct agonists, only elevating $\mathrm{eCB}$ signaling where it is active and it is more likely that it will be the preferred approach to elevate CB1r activity pharmacologically in humans, given the adverse effects of direct agonists [15].

The reactivation of previously consolidated memories may trigger a process of destabilization and lability of the memory trace termed reconsolidation [16]. URB597-induced changes in fear retrieval may occur either via reconsolidation inhibition or extinction facilitation. To differentiate between the two processes, we chose to administer the drugs with or without specific pairing with reactivation of the memory trace; URB597 was administered $5 \mathrm{~min}$ (paired) or $24 \mathrm{~h}$ (unpaired) after exposure to a reminder of the shock. Drugs were paired with exposure to the second reminder as this may be more relevant to humans, being exposed to reminders of the trauma (and usually not for the first time) when being treated pharmacologically.

Our second aim was to examine whether URB597 will modulate metaplastic effects in the BLA and CA1 induced by exposure to shock and reminders. Metaplasticity describes the way in which synaptic plasticity is regulated by prior synaptic activity [17]. Exposure to stress was suggested to induce behavioral metaplasticity [18] similar to that observed after amygdala priming [19, 20]. Behavioral metaplasticity involves altered plasticity at the level of the neural systems following exposure to stress. We have shown that exposure to shock and reminders induced metaplasticity in the CA1 and BLA [6].

Exposure to shock and reminders might cause variation in endogenous cannabinoid levels that could affect fear-circuit function. Hence, we examined whether exposure to shock and reminders will trigger alteration in the endogenous system in the BLA and CA1 that could affect BLA-CA1 function to promote an enhanced fear response.

\section{METHODS AND MATERIALS \\ Subjects}

Male Sprague-Dawley rats ( 60 days old, $\sim 250 \mathrm{~g}$; Harlan, Jerusalem, Israel) were grouped housed at $22 \pm 2{ }^{\circ} \mathrm{C}$ under 12-h light/dark cycles (lights turned on at 07:00). Rats were allowed water and laboratory rodent chow ad libitum. All experiments were approved by the University of Haifa Ethics and Animal Care Committee, and adequate measures were taken to minimize pain or discomfort.

\section{Drug treatment}

URB597 (URB; $0.3 \mathrm{mg} / \mathrm{kg}$ i.p.; $0.1 \mu \mathrm{g} / 0.5 \mu \mathrm{l}$ ) and AM251 (0.3 mg/kg, $3 \mathrm{mg} / \mathrm{kg}$ i.p.; $0.01 \mu \mathrm{g} / 0.5 \mu \mathrm{l}$ ) (Cayman Chemicals) were dissolved in $1 \%$ dimethylsulfoxide (DMSO), 1\% Tween-80, and 98\% saline. Controls were given the vehicle (Veh) only. Drug doses were based on previous reports $[6,21,22]$.

Shock, situational reminders (SRs), and extinction Rats were placed in an inhibitory avoidance apparatus (for details see [7]).

Shock (conditioning). Each rat was placed in the light compartment. Thirty seconds after the rat entered the dark compartment, the door closed and the rat received an inescapable $1.5 \mathrm{~mA}$ shock for $10 \mathrm{~s}$.
Situational reminders. Rats were placed in the light compartment for $1 \mathrm{~min}$ with the gate closed in order to prevent them from entering the shock compartment (to avoid extinction).

Fear retrieval and extinction. Rats were submitted to a nonreinforced test trial every $24 \mathrm{~h}$ for 3 days starting on day 5 . Each rat was placed in the light side of the box, and the time elapsed until it crossed over to the dark side (i.e., latency) was measured. The first extinction trial is also indicative of fear retrieval (Ret/Ext1).

\section{Electrophysiology}

The methods for electrophysiology are essentially as described in Ref. [6]. Briefly, in anesthetized rats, a recording microelectrode was inserted into the CA1 or BLA and a bipolar, $125 \mu \mathrm{m}$ stimulating electrode was placed in the schaffer collateral (SC) region or the ventral subiculum (vSub), respectively (see coordinates below).

\begin{tabular}{llll} 
& Anteroposterior $(\mathrm{mm})$ & Lateral $(\mathrm{mm})$ & Ventral $(\mathrm{mm})$ \\
\hline CA1 & -4.2 & \pm 2.5 & -2.0 \\
SC & -3.1 & \pm 0.4 & -3.5 \\
vSub & -6.5 & \pm 5.0 & -6.0 \\
BLA & -2.2 & \pm 5.0 & -7.5
\end{tabular}

Evoked field potentials (EFPs) were digitized $(10 \mathrm{kHz})$ and analyzed using Cambridge Electronic Design (CED, Cambridge, UK). Test stimuli (monopolar pulses, $100 \mu \mathrm{s}$ duration) were delivered at $0.1 \mathrm{~Hz}$. Long-term potentiation (LTP) was induced by high-frequency stimulation (HFS) (3 sets of 10 trains; each train consisting of 10 pulses at $200 \mathrm{~Hz}$; intertrain interval, $200 \mathrm{~ms}$; interset interval, $1 \mathrm{~min}$ ) to the SC or vSub.

Cannulation and drug microinjection

Anesthetized rats were implanted bilaterally with a stainless steel guide cannula aimed at the dorsal CA1 or the BLA (see [13]).

For microinjection, a volume of $0.5 \mu \mathrm{l}$ per side was microinjected bilaterally over a period of $1 \mathrm{~min}$. using a microinfusion pump (CMA/100; Carnegie Medicine, Stockholm, Sweden).

Biochemical analysis of eCB content

Rats were decapitated $100 \mathrm{~min}$ or $24 \mathrm{~h}$ after exposure to the second SR. CA1 and BLA were subjected to a lipid extraction process as described previously [23].

ECBs were measured using isotope-dilution; deuterated analogs of AEA and 2-AG $\left(\left[{ }^{2} \mathrm{H}_{8}\right]\right.$ AEA and $\left.\left[{ }^{2} \mathrm{H}_{8}\right] 2-\mathrm{AG}\right)$ were used to assess the recovery of endogenous lipids during the extraction process. Tissue samples were weighed and homogenized in $2 \mathrm{ml}$ of acetonitrile containing $4500 \mathrm{pg}$ of $\left[{ }^{2} \mathrm{H}_{8}\right] A E A$ and $18 \mathrm{ng}$ of $\left[{ }^{2} \mathrm{H}_{8}\right] 2-$ AG. Following bath sonication for $30 \mathrm{~min}$, samples were incubated $30 \mathrm{~min}$ at $-80^{\circ} \mathrm{C}$ to precipitate proteins, then centrifuged at $1500 \times g$ for 3 min to remove particulates. After drying under $\mathrm{N}_{2}$, samples were resuspended in $500 \mu \mathrm{l}$ of methanol and dried again under $\mathrm{N}_{2}$ gas. Final lipid extracts were suspended in $30 \mu \mathrm{l}$ of methanol and stored at $-80^{\circ} \mathrm{C}$ until analysis. The contents of AEA and 2-AG were determined in the lipid extracts using liquid chromatography-mass spectrometry-mass spectroscopy (LC/MS/ MS) as described previously [24].

Activities of FAAH and MAGL were determined at a single concentration of substrate as described previously [25]. Membranes and cytosol were both harvested from homogenates of the tissues; FAAH activity was determined in the membrane fraction while MAGL activity was determined in the cytosolic fraction, in the presence of the FAAH inhibitor URB597 $(1 \mu \mathrm{M})$ to block any residual FAAH activity in this fraction. Activity was normalized to protein concentrations measured in the same sample. 
Statistical analysis

The results are expressed as means \pm SEM. Analysis of variance (ANOVA) was used as indicated. All post hoc comparisons were made using Tukey's range test. Significance was determined as $p<0.05$.

\section{RESULTS}

Experiment 1: the effects of URB597 administered systemically before extinction on fear

We examined the effects of systemically enhancing and blocking the eCB system of rats exposed to shock and reminders on extinction. Drugs were administered immediately following exposure to the second SR (SR2; see Fig. 1a for study design) or $24 \mathrm{~h}$ after SR2 (see Fig. 1c for study design). We used a low dose of the $\mathrm{CB} 1 \mathrm{r}$ antagonist AM251 $(0.3 \mathrm{mg} / \mathrm{kg})$ to block CB1r as previous results have demonstrated that a low dose of this antagonist had no effect on behavior by itself, but it prevented the therapeutic effects of the cannabinoid agonists $[6,13]$. Hence, AM251 and URB597 were administered concurrently in order to examine the involvement of CB1rs in the effects of the FAAH inhibitor on fear retrieval and extinction.

When drugs were injected immediately after SR2, a two-way ANOVA with repeated measures [(treatment $\times$ extinction $(5 \times 5)$ ] on the latency to enter the dark side revealed significant effects of treatment $\left(F_{(4,30)}=16.892, p<0.001\right)$, extinction $\left(F_{(2,60)}=17.300\right.$, $p<0.001)$, and interaction $\left(F_{(8,60)}=2.169, p<0.05\right)$ (Fig. 1b). Post hoc tests revealed significant differences between the No ShockSR Veh and Shock-SR URB groups to the other groups on fear retrieval (Ret/Ext1) and Ext2 $(p<0.05)$. The No Shock-SR Veh group was different from the Shock-SR Veh group on Ext3 and Spon. Recov. $(p<0.05)$. These findings suggest that URB decreased fear retrieval and this effect persisted throughout extinction training (Ext2 and Ext3), and remained minimal during the spontaneous recovery test. The effects of URB were CB1r-dependent since coadministration of AM251 and URB resulted in a significantly greater latency to enter the dark side than treatment with URB alone on all extinction days. The latency in the Shock-SR AM251 group was not different from the Shock-SR Veh group.

A similar effect was observed when the drugs were administered $24 \mathrm{~h}$ after SR2. A two-way ANOVA with repeated measures $(3 \times 5)$ on latency revealed significant effects of treatment $\left(F_{(2,19)}=25.565, p<0.001\right)$, extinction $\left(F_{(2,38)}=55.987, p<0.001\right)$ and interaction $\left(F_{(4,38)}=4.856, p<0.01\right)$ (Fig. 1d). Post hoc tests revealed significant differences between the Shock-SR Veh group and the two other groups on Ret/Ext1, Ext2, Ext3, and Spon. Recov. $(p<0.05)$. Hence, URB decreased fear retrieval and this effect persisted throughout extinction training and did not recuperate during spontaneous recovery. This suggests that administering URB prior to extinction abolished the fear response, even when drug administration was not paired with exposure to the reminder.

As a control experiment we added two groups: (1) injected with vehicle or URB i.p. after SR2 and tested for fear retrieval after $24 \mathrm{~h}$, or (2) exposed to SR2 on day 5, injected i.p. on day 6 and tested for fear retrieval on day 7, $48 \mathrm{~h}$ after SR2 (see Fig. S1A for study design).

A two-way ANOVA with repeated measures $(3 \times 4)$ on latency revealed significant effects of extinction $\left(F_{(2,36)}=33.280, p<\right.$ 0.001 ), but not of treatment or interaction (Fig. S1B). However, it seems that the Shock-SR URB $24 \mathrm{~h}$ group showed decreased latency on Ext2 compared to the two other groups (one way ANOVA: $\left.F_{(2,20)}=3.261, p=0.05\right)$. This suggests that when URB was administered after SR2 and fear retrieval was assessed $24 \mathrm{~h}$ later, there was a significant facilitation in extinction with no effect on fear retrieval. When URB was administered $24 \mathrm{~h}$ after SR2 and fear retrieval assessed $24 \mathrm{~h}$ later (the $48 \mathrm{~h}$ group), no effect of URB was observed on fear retrieval or extinction. The findings suggest that
A Shock SR1 SR2


C Shock SR1 SR2
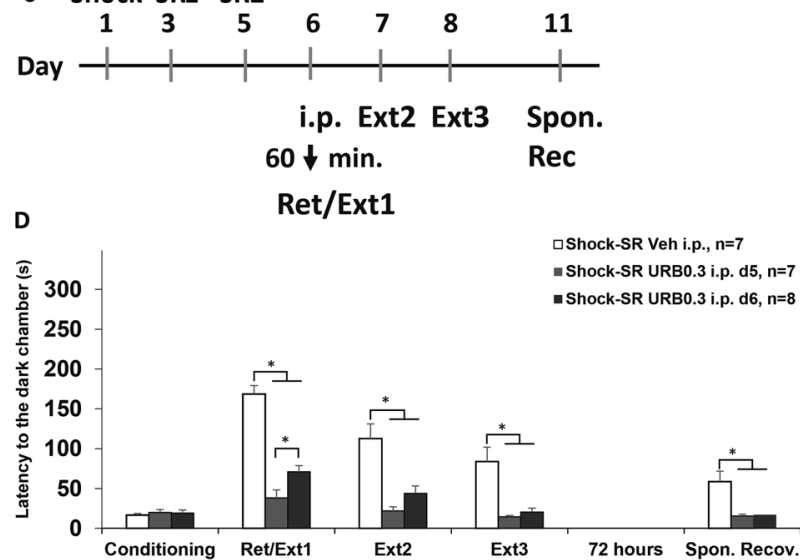

Fig. 1 URB597 administered systemically before extinction attenuated fear. a $A$ diagram illustrating the experimental design. Rats were exposed to shock $(1.5 \mathrm{~mA}, 10 \mathrm{~s})$ or not on day 1 and to a situational reminder (SR) on days 3 and 5 . One hour after SR on day 5 , rats were taken for fear retrieval/first extinction trial (Ret/Ext1). Drugs were i.p. injected $5 \mathrm{~min}$ after SR exposure. Additional extinction trials were carried out on days 6 and 7 (Ext2, Ext3). After $72 \mathrm{~h}$ another extinction trial was carried out to assess spontaneous recovery (Spon. Recov.). b The Shock-SR Veh, Shock-SR AM and Shock-SR URB + AM groups demonstrated increased latency to enter the dark side on Ret/Ext1 and Ext2 compared to the No ShockSR Veh and Shock-SR URB groups. Also, the Shock-SR Veh group showed increased latency on Ext3 and Spon. Recov. compared to the No Shock-SR Veh group $\left({ }^{*} p<0.05\right)$. c A diagram illustrating the experimental design. Rats were exposed to shock $(1.5 \mathrm{~mA}, 10 \mathrm{~s})$ or not on day 1 and to a situational reminder (SR) on days 3 and 5 . Twenty-four hours after SR2, rats were i.p. injected with the drugs and taken for fear retrieval/first extinction trial (Ret/Ext1). Additional extinction trials were carried out on days 7 and 8 (Ext2, Ext3). After $72 \mathrm{~h}$ another extinction trial was carried out to assess spontaneous recovery (Spon. Recov.). d The Shock-SR Veh group demonstrated increased latency to enter the dark side on Ret/Ext1, Ext2, Ext3, and Spon. Recov. compared to the Shock-SR URB d5 (drugs administered immediately after SR2) and the Shock-SR URB d6 (drugs administered $24 \mathrm{~h}$ after SR2) groups $\left({ }^{*} p<0.05\right)$

URB administered after reminder exposure or prior to fear retrieval facilitate extinction.

Experiment 2: the effects of URB597 microinjected into the hippocampus and amygdala before extinction on fear We examined the effects of locally microinjecting URB597 and AM251 in the CA1 and BLA of rats exposed to shock and reminders on extinction (see Fig. 2a for study design).

When drugs were microinjected into the CA1 immediately after SR2, a two-way ANOVA with repeated measures $(5 \times 3)$ on latency 
A
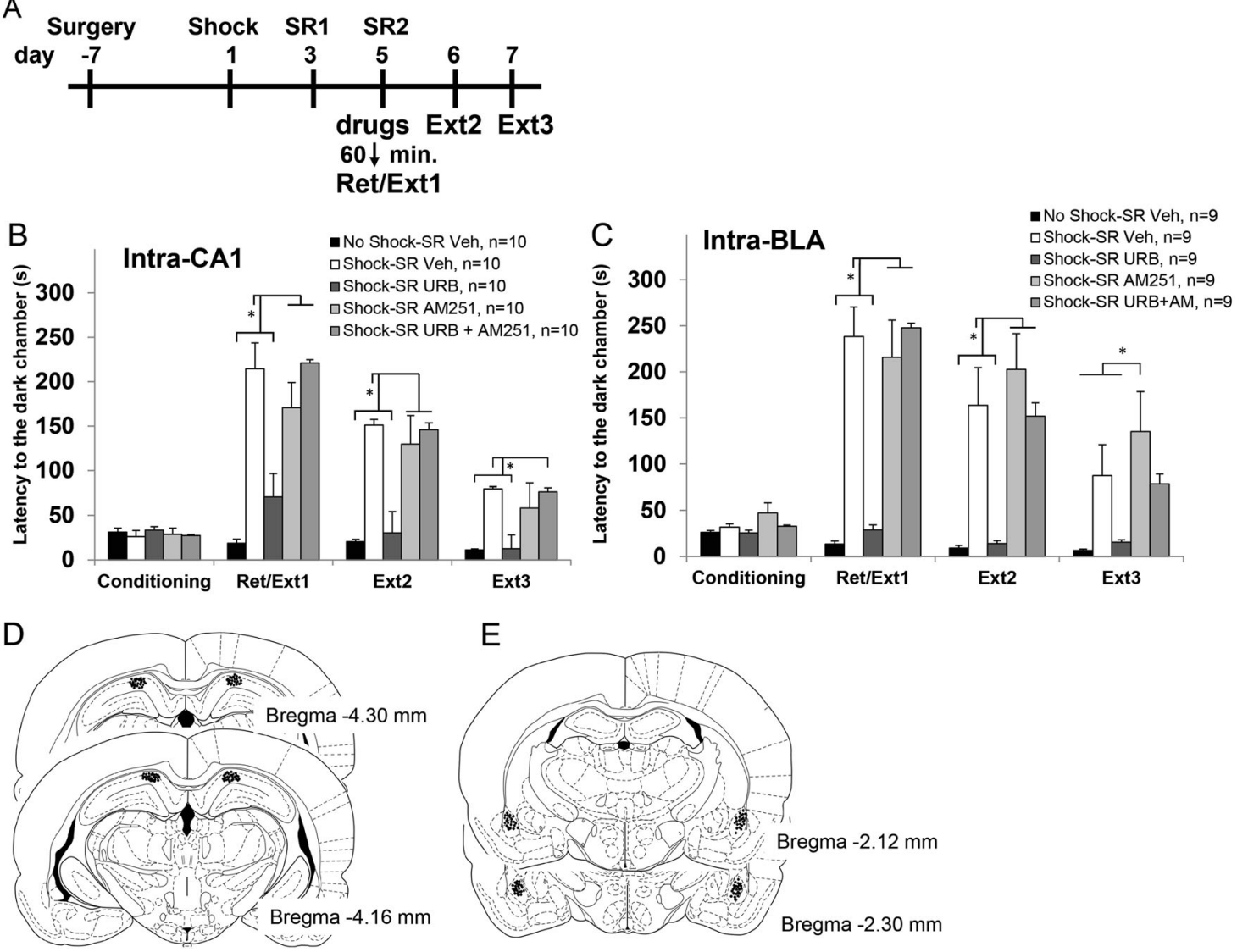

Fig. 2 URB597 microinjected into the hippocampus and amygdala before extinction attenuated fear. a A diagram illustrating the experimental design. Rats were implanted with cannulae into the CA1 or BLA and left for 1-week recovery. Rats were exposed to shock or not on day 1 and to a situational reminder (SR) on days 3 and 5 . Immediately after SR exposure on day 5, rats were microinjected with the drugs into the CA1 or BLA and after $1 \mathrm{~h}$ taken for fear retrieval/first extinction trial. Additional extinction trials were carried out on days 6 and 7 (Ext2, Ext3). $\mathbf{b}$ In the CA1, the No Shock-SR Veh and Shock-SR URB groups demonstrated reduced latency to enter the dark side compared to the Shock-SR Veh, Shock-SR AM251 and Shock-SR URB + AM251 groups on Ret/Ext1 and Ext2. Further, the Shock-SR Veh and Shock-SR URB + AM251 groups demonstrated increased latency compared to the No Shock-SR Veh and Shock-SR URB groups on Ext3 ( $\left.{ }^{*} p<0.05\right)$. c In the BLA, the No Shock-SR Veh and Shock-SR URB groups demonstrated reduced latency to enter the dark side compared to the Shock-SR Veh, ShockSR AM251 and Shock-SR URB + AM251 groups on Ret/Ext1 and Ext2. On Ext3, the Shock-SR AM251 group differed from the No Shock-SR Veh and Shock-SR URB groups $(*<0.05)$. d Representative schematic drawing of cannula tip positions in the CA1. A coronal view at position -4.30 and $-4.16 \mathrm{~mm}$ posterior to bregma. e Representative schematic drawing of cannula tip positions in the BLA. A coronal view at position -2.12 and $-2.30 \mathrm{~mm}$ posterior to bregma

revealed significant effects of treatment $\left(F_{(3,36)}=17.351, p<\right.$ $0.001)$, extinction $\left(F_{(2,90)}=62.77, p<0.001\right)$ and interaction $\left(F_{(6,72)}=5.09, p<0.001\right) \quad$ (Fig. 2b). Post hoc tests revealed significant differences between the Shock-SR Veh and Shock-SR URB groups on all extinction days $(p<0.5)$. This effect was CB1rdependent, as co-administration of AM251 and URB resulted in a significantly greater latency than treatment with URB alone on all extinction days $(p<0.05)$. Latency in the Shock-SR AM251 group was not different from the Shock-SR Veh group.

A very similar and even more profound effect of URB597 was seen when it was injected into the BLA immediately after SR2 (Fig. 2c). Two-way ANOVA with repeated measures $(5 \times 3)$ on latency revealed significant effects of treatment $\left(F_{(4,42)}=22.46\right.$, $p<0.001)$, extinction $\left(F_{(2,84)}=28.989, p<0.001\right)$, and interaction $\left(F_{(8,84)}=3.544, p<0.001\right)$. Post hoc tests revealed significant differences in latency during Ret/Ext1 and Ext2 between the Shock-SR URB group and both the Shock-SR Veh and Shock-SR URB + AM251 groups $(p<0.05)$. The results suggest that intra-BLA URB abolished fear retrieval and that this effect on fear retrieval is CB1 receptor dependent.
Representative schematic drawing of cannula tip positions are shown for the CA1 (Fig. 2d) and BLA (Fig. 2e).

Similar effects were observed when drugs were microinjected $24 \mathrm{~h}$ after SR2 (see Fig. S2A for study design). In the CA1, a twoway ANOVA with repeated measures $(3 \times 4)$ on latency revealed significant effects of treatment $\left(F_{(2,18)}=21.932, p<0.001\right)$, extinction $\left(F_{(2,36)}=15.943, p<0.001\right)$ and interaction $\left(F_{(4,36)}=5.177, p<\right.$ $0.01)$ (Fig. S2B). Post hoc tests revealed a significant increase in latency in the Shock-SR Veh group compared to the other groups on Ret/Ext1, Ext2, and Ext3 $(p<0.05)$. Hence, URB administered into the CA1 prior to extinction, immediately or $24 \mathrm{~h}$ after SR2, attenuated fear.

In the BLA, a two-way ANOVA with repeated measures $(3 \times 4)$ on latency revealed significant effects for treatment $\left(F_{(2,17)}=\right.$ $20.961, p<0.001)$, extinction $\left(F_{(2.36)}=5.749, p<0.05\right)$, and interaction $\left(F_{(4,36)}=2.994, p<0.001\right)$ (Fig. S2C). Post hoc tests revealed significant differences between the Shock-SR Veh and the other groups on Ret/Ext1 and Ext2 $(p<0.05)$. As shown in the CA1, URB administered into the BLA prior to extinction, immediately or $24 \mathrm{~h}$ after SR2, attenuated fear. 
Experiment 3: the effects of URB597 administered systemically before hippocampal LTP induction in rats exposed to shock and reminders

We examined the effects of exposure to shock and reminders on LTP in the CA1 (see Fig. 3a for study design). A three-way ANOVA with repeated measures [(Shock $\times \mathrm{SR} \times$ time $(2 \times 2 \times 12)]$ on postHFS EFPs amplitude (Fig. 3b) in the CA1 revealed a significant effect of $\operatorname{shock}\left(F_{(1,32)}=38.608, p<0.001\right)$, SR $\left(F_{(1,32)}=104.547, p<\right.$ $0.001)$ and interaction $\left(F_{(1,32)}=13.674, p<0.001\right)$. Post hoc analysis revealed a significant difference between the Shock-SR group to all other groups in amplitude $(p<0.05)$. This indicates that exposure to shock and SRs impaired LTP in the CA1. In addition, the No shock-SR group showed lower amplitude compared with the No shock-No SR and Shock-No SR groups $(p<0.05)$, suggesting an effect of SR exposure on CA1-LTP.

A three-way ANOVA with repeated measures on amplitude preHFS [shock $\times \mathrm{SR} \times$ time $(2 \times 2 \times 6)$ ] did not reveal any significant effects, suggesting a similar baseline between the groups before HFS was applied.

To examine the effects of stress and SRs on baseline synaptic activity, input-output measurements were taken. A three-way ANOVA with repeated measures [Shock $\times \mathrm{SR} \times$ stimulation intensity $(2 \times 2 \times 5)$ ] revealed a significant effect for stimulation intensity on amplitude $\left(F_{(4,120)}=49.645, p<0.001\right.$; Fig. 3c). Yet, stimulation of the SC input into the CA1 with different stimulus intensities did not result in any other significant effects on basal EFPs suggesting no effect on baseline synaptic activity. Representative signal traces in the CA1 taken before and $1 \mathrm{~h}$ after HFS to the SC are shown (Fig. 3d).

Next, we examined the effects of systemically enhancing and blocking the $\mathrm{eCB}$ system in rats exposed to shock and reminders on LTP in the CA1 (see Fig. 3e for study design). Post-HFS analysis $(3 \times 12)$ on CA1 EFPs amplitude (Fig. $3 f)$ indicated a significant effect for group $\left(F_{(3,22)}=20.758, p<0.001\right)$. Post hoc analysis revealed a significant difference between the Shock-SR URB group and the Shock-SR Veh and Shock-SR AM251 groups in amplitude $(p<0.05)$. These results demonstrate that systemic URB administered immediately after SR2 prevented the shock/SR-induced impairment in LTP.

To evaluate the effects of the drugs on CA1-LTP per se, with no stress exposure, we examined the effects of systemically enhancing (URB $0.3 \mathrm{mg} / \mathrm{kg}$ ) and blocking (AM251 $3 \mathrm{mg} / \mathrm{kg}$ ) the eCB system on LTP in nonstressed rats (see Fig. $3 \mathrm{~g}$ for study design). We used a high dose of AM251 (3 mg/kg) to block CB1r activation.

Post-HFS analysis $(3 \times 12)$ on EFPs amplitude (Fig. 3 h) indicated a significant effect for group $\left(F_{(2,18)}=11.056, p<0.001\right)$. Post hoc analysis revealed a significant difference between the Vehicle group and the URB and AM251 groups $(p<0.05)$. This suggests that injecting URB i.p. before HFS attenuated LTP in the CA1, and that the effects of URB on LTP per se is different than the effect observed in stressed rats.

Pre-HFS analysis $(3 \times 6)$ on EFPs amplitude did not reveal any significant effects.

Next we examined whether the effects of URB on LTP are CB1rdependent using a low dose of the CB1r antagonist AM251 (0.3 $\mathrm{mg} / \mathrm{kg})$. Post-HFS analysis $(3 \times 12)$ on EFPs amplitude (Fig. 3i) indicated a significant effect for group $\left(F_{(3,24)}=56.888, p<0.001\right)$. Post hoc analysis revealed a significant difference between the No Shock-SR Veh group and all the other groups $(p<0.05)$, suggesting that AM251 blocked the effects of URB on LTP in the CA1 in stressed rats.

Pre-HFS analysis $(3 \times 6)$ on EFPs amplitude did not reveal any significant effects.

As a control experiment, drugs were injected $24 \mathrm{~h}$ after SR2 (see Fig. S3A for study design of the Shock-SR URB CA1 d6 group) or immediately after SR2 (see Fig. 3e for study design of the Shock-SR URB CA1 d5 group). Post-HFS analysis $(3 \times 12)$ on EFPs amplitude (Fig. S3B) indicated a significant effect of group $\left(F_{(2,18)}=21.051\right.$, $p<0.001)$. Post hoc analysis revealed a significant difference between the Shock-SR Veh group and all the other groups $(p<$ $0.05)$, suggesting that URB prevented the effects of shock and reminders on LTP in the CA1 when injected $24 \mathrm{~h}$ after the reminder.

Pre-HFS analysis $(3 \times 6)$ on EFPs amplitude did not reveal any significant effects.

Experiment 4: the effects of URB597 administered systemically before BLA-LTP induction in rats exposed to shock and reminders We examined the effects of exposure to shock and SRs on LTP in the BLA (see Fig. 4a for study design). Post-HFS analysis on EFPs amplitude (Fig. 4b) in the BLA revealed significant effects of shock $\left(F_{(1,22)}=10.039, p<0.01\right)$. Post hoc analysis revealed a significant difference between the Shock-SR group and the other groups $(p<$ 0.05 ) indicating that the shock-SR group demonstrated higher potentiation levels.

Pre-HFS analysis on amplitude $(2 \times 2 \times 6)$ did not reveal any significant effects.

When we examined baseline synaptic activity, a significant effect for stimulation intensity on amplitude was found $\left(F_{(4,88)}=\right.$ $57.31, p<0.001$; Fig. 4c). Yet, stimulation of the vSub input into the BLA with different stimulus intensities did not result in any other significant effects on basal EFPs suggesting no effect on baseline synaptic activity.

Representative signal traces in the BLA taken before and $1 \mathrm{~h}$ after HFS to the vSub are shown (Fig. 4d).

Next, we examined the effects of systemically enhancing and blocking the eCB system in rats exposed to shock and reminders on BLA-LTP (see Fig. 4e for study design).

Post-HFS analysis $(3 \times 12)$ on EFPs amplitude (Fig. $4 f)$ indicated a significant effect for group $\left(F_{(2,22)}=59.55, p<0.001\right)$. Post hoc analysis revealed a significant difference between the Shock-SR Veh group to the Shock-SR URB and shock-SR AM251 groups ( $p<$ 0.05). Further, the Shock-SR URB group showed a significant difference in amplitude from the Shock-SR AM251 group $(p<$ 0.05). Thus, URB prevented the effects of the shock/SR on LTP, whereas a high dose of AM251 (3 mg/kg) impaired LTP.

Pre-HFS analysis on amplitude pre-HFS $(3 \times 6)$ did not reveal any significant effects.

To evaluate the effects of the drugs on BLA-LTP per se, we examined the effects of systemically enhancing and blocking the eCB system on LTP in nonstressed rats (see Fig. $4 \mathrm{~g}$ for study design). Post-HFS analysis using two-way ANOVA with repeated measures $(3 \times 12)$ on EFPs amplitude (Fig. 3h) indicated a significant effect of group $\left(\mathrm{F}_{(2,17)}=3.982, \mathrm{p}<0.05\right)$. Post hoc analysis revealed a significant difference between the Vehicle and the URB groups and the AM251 group $(p<0.05)$. Hence, injecting a high dose of AM251 (3 mg/kg) before HFS impaired LTP in the BLA.

Pre-HFS analysis on amplitude $(3 \times 6)$ did not reveal any significant effects.

Next we examined whether the effects of URB on BLA-LTP are CB1r-dependent using a low dose of AM251 (0.3 mg/kg). Post-HFS analysis $(3 \times 12)$ on EFPs amplitude (Fig. 4i) indicated a significant effect of group $\left(F_{(3,24)}=13.898, p<0.001\right)$. Post hoc analysis revealed a significant difference between the No Shock-SR Veh group and the Shock-SR Veh and Shock-SR AM groups $(p<0.05)$. Further, the Shock-SR Veh group was significantly different from the Shock-SR URB + AM group $(p<0.05)$. The results suggest that a low dose of AM251 $(0.3 \mathrm{mg} / \mathrm{kg})$ did not block the effects of URB on LTP in the BLA in stressed rats, and that the effects of URB on BLA-LTP in stressed rats is not CB1r-dependent.

Pre-HFS analysis $(3 \times 6)$ on EFPs amplitude did not reveal any significant effects.

When drugs were injected $24 \mathrm{~h}$ after SR2 (see Fig. S4A for study design), post-HFS analysis $(3 \times 12)$ on EFPs amplitude (Fig. S4B) indicated a significant effect for group $\left(F_{(2,17)}=26.980, p<0.001\right)$. 

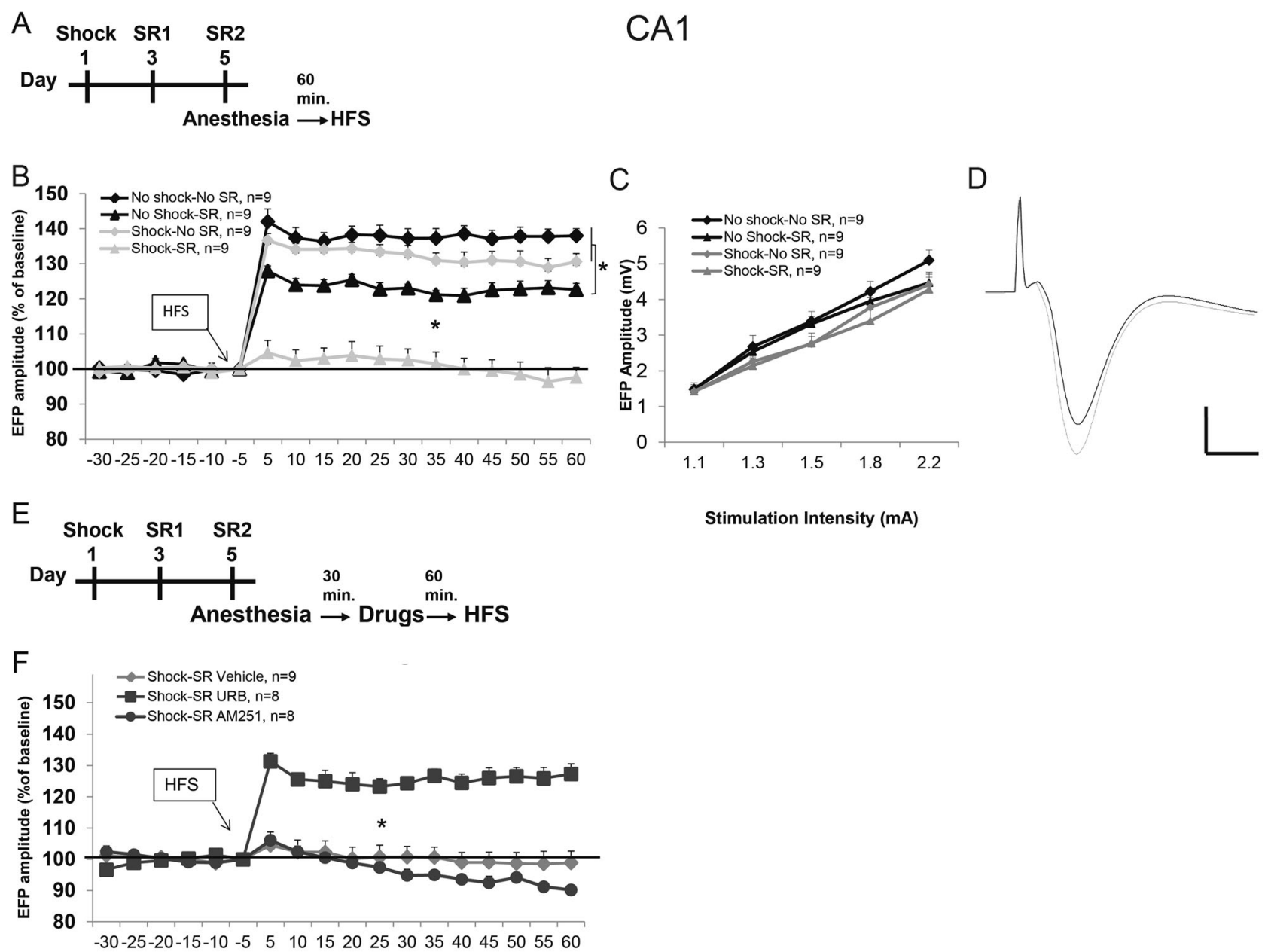

Stimulation Intensity (mA)

G

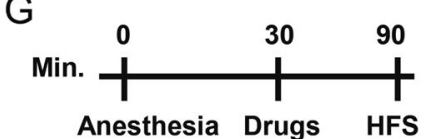

$\mathrm{H}$
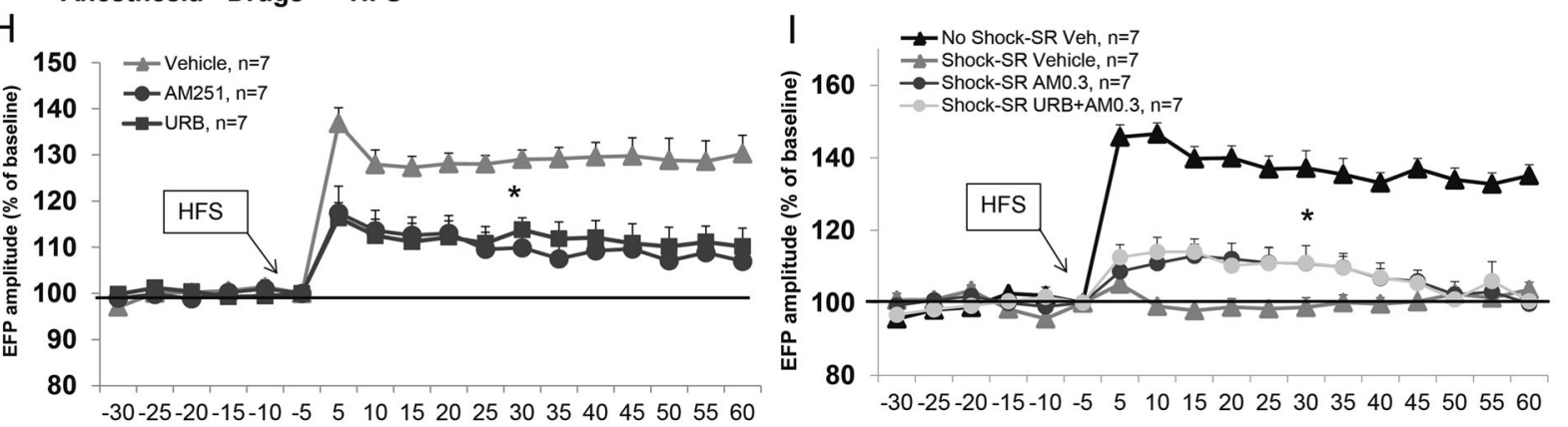

Fig. 3 The effects of URB597 administered systemically before hippocampal LTP in rats exposed to shock and reminders. a A diagram illustrating the experimental design. Rats were exposed to shock or not on day 1 and to a situational reminder (SR) on days 3 and 5 . Immediately after SR exposure on day 5, rats were anesthetized and taken for electrophysiological recording. HFS was induced $1 \mathrm{~h}$ after SR. b In the CA1, the Shock-SR group demonstrated significantly reduced amplitude levels compared to all groups post-HFS. The No shock-SR group showed reduced amplitude levels compared with the No shock-No SR and Shock-No SR groups post-HFS ( $\left.{ }^{*} p<0.05\right)$. c Input-output curve: no significant differences between the groups were found in CA1 EFP amplitude after stimulation of SC input with different stimulus intensities. d Representative signal trace in the CA1 taken before (black line) and $1 \mathrm{~h}$ after (gray line) HFS to the SC (calibration: $0.5 \mathrm{mV}, 10 \mathrm{~ms}$ ). e A diagram illustrating the experimental design. Rats were exposed to shock or not on day 1 and to SR on days 3 and 5 . Immediately after SR exposure on day 5, rats were anesthetized and taken for electrophysiological recording. Drugs were administered i.p. 30-40 min after SR. HFS was induced $1 \mathrm{~h}$ after drug exposure. $\mathrm{f}$ In the CA1, the Shock-SR URB group demonstrated significantly increased amplitude levels compared to all groups post-HFS ( $\left.{ }^{*} p<0.05\right)$. g A diagram illustrating the experimental design. Rats were anesthetized and taken for electrophysiological recording (no shock or SR). Drugs were administered i.p. 30-40 min after SR. HFS was induced $1 \mathrm{~h}$ after drug exposure. $\mathbf{h}$ In the CA1, the Vehicle group demonstrated significantly increased amplitude levels compared to all groups post-HFS ( $\left.{ }^{*} p<0.05\right)$. (i) The Shock-SR Veh, ShockSR AM0.3, and Shock-SR URB + AM0.3 groups demonstrated impaired LTP in the BLA compared to the No Shock-SR Veh group ( $\left.{ }^{*} p<0.05\right)$ 
A

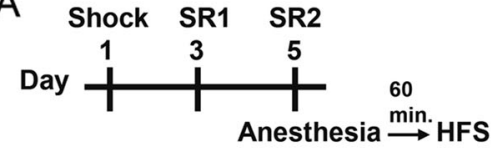

B

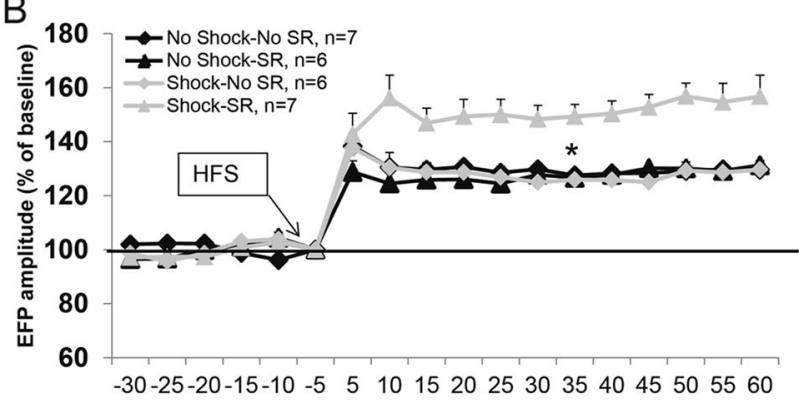

E

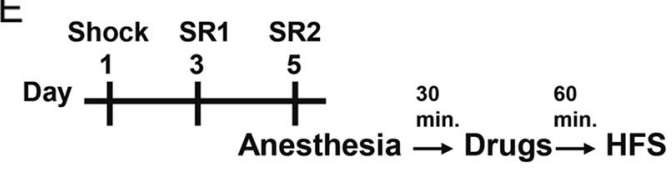

F

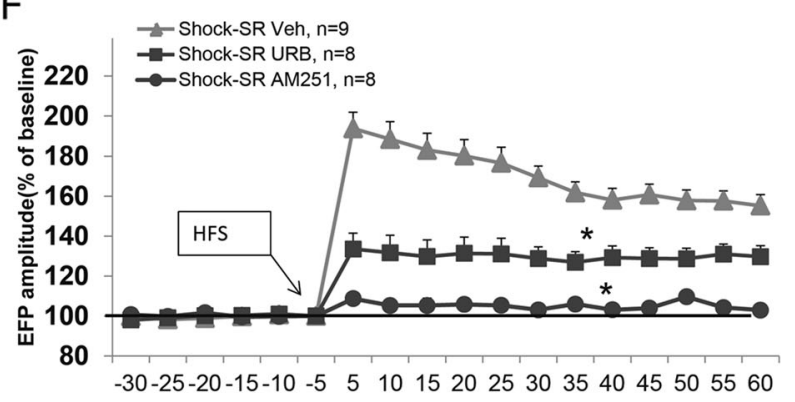

G

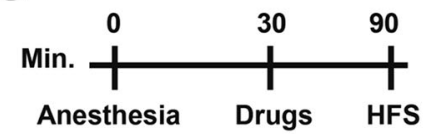

$\mathrm{H}$

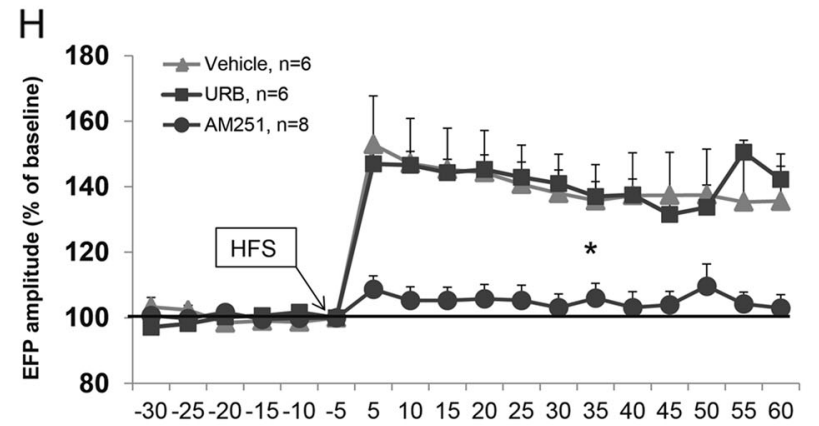

BLA

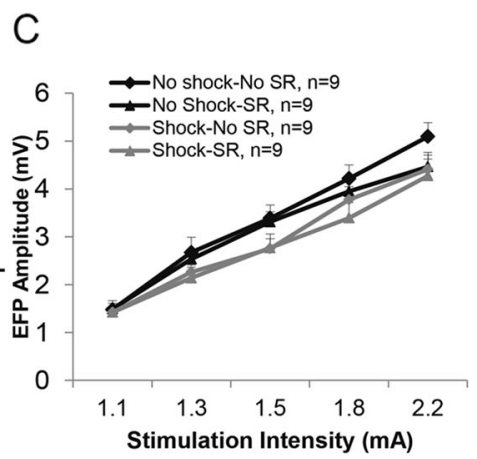

D

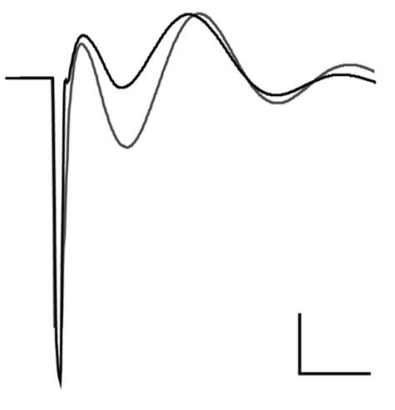

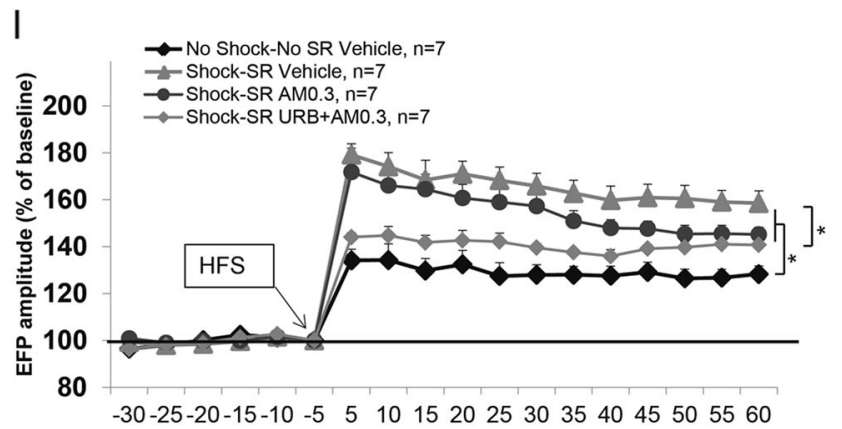

Fig. 4 The effects of URB597 administered systemically before BLA-LTP in rats exposed to shock and reminders. a A diagram illustrating the experimental design. Rats were exposed to shock or not on day 1 and to a situational reminder (SR) on days 3 and 5. Immediately after SR exposure on day 5, rats were anesthetized and taken for electrophysiological recording. HFS was induced $1 \mathrm{~h}$ after SR. b In the BLA, the ShockSR group demonstrated significantly enhanced amplitude levels compared to all groups post-HFS $\left({ }^{*} p<0.05\right)$. c Input-output curve: no significant differences between the groups were found in BLA EFP amplitude after stimulation of SC input with different stimulus intensities. d Representative signal trace in the BLA taken before (black line) and $1 \mathrm{~h}$ after (gray line) HFS to the vSub (calibration: $0.5 \mathrm{mV}, 10 \mathrm{~ms}$ ). e A diagram illustrating the experimental design. Rats were exposed to shock or not on day 1 and to SR on days 3 and 5. Immediately after SR exposure on day 5, rats were anesthetized and taken for electrophysiological recording. Drugs were administered i.p. 30-40 min after SR. HFS was induced $1 \mathrm{~h}$ after drug exposure. $\mathbf{f}$ In the BLA, the Shock-SR Vehicle group demonstrated significantly increased amplitude levels compared to all groups post-HFS. The Shock-SR AM251 group showed reduced amplitude levels compared to the Shock-SR URB group ( $p<$ 0.05). g A diagram illustrating the experimental design. Rats were anesthetized and taken for electrophysiological recording (no shock or SR). HFS was induced $1 \mathrm{~h}$ after drug exposure. $\mathbf{h}$ In the BLA, the AM251 group demonstrated significantly reduced amplitude levels compared to all groups post-HFS ( $\left.{ }^{*} p<0.05\right)$. i The Shock-SR Veh and Shock-SR AM0.3 groups demonstrated enhanced LTP compared to the No Shock-SR Veh group. Further, the Shock-SR Veh group was significantly different from the Shock-SR URB + AM groups $\left({ }^{*} p<0.05\right)$ 


\section{A

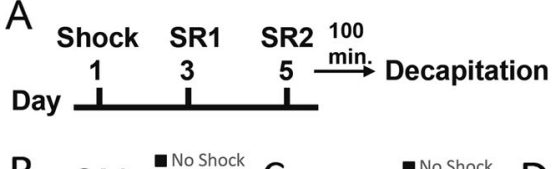

B CA1 $\underset{\text { aShock }}{\text { anoshock }} \mathrm{C} \quad$ BLA $\underset{\square \text { Shock }}{\text { moshock }}$
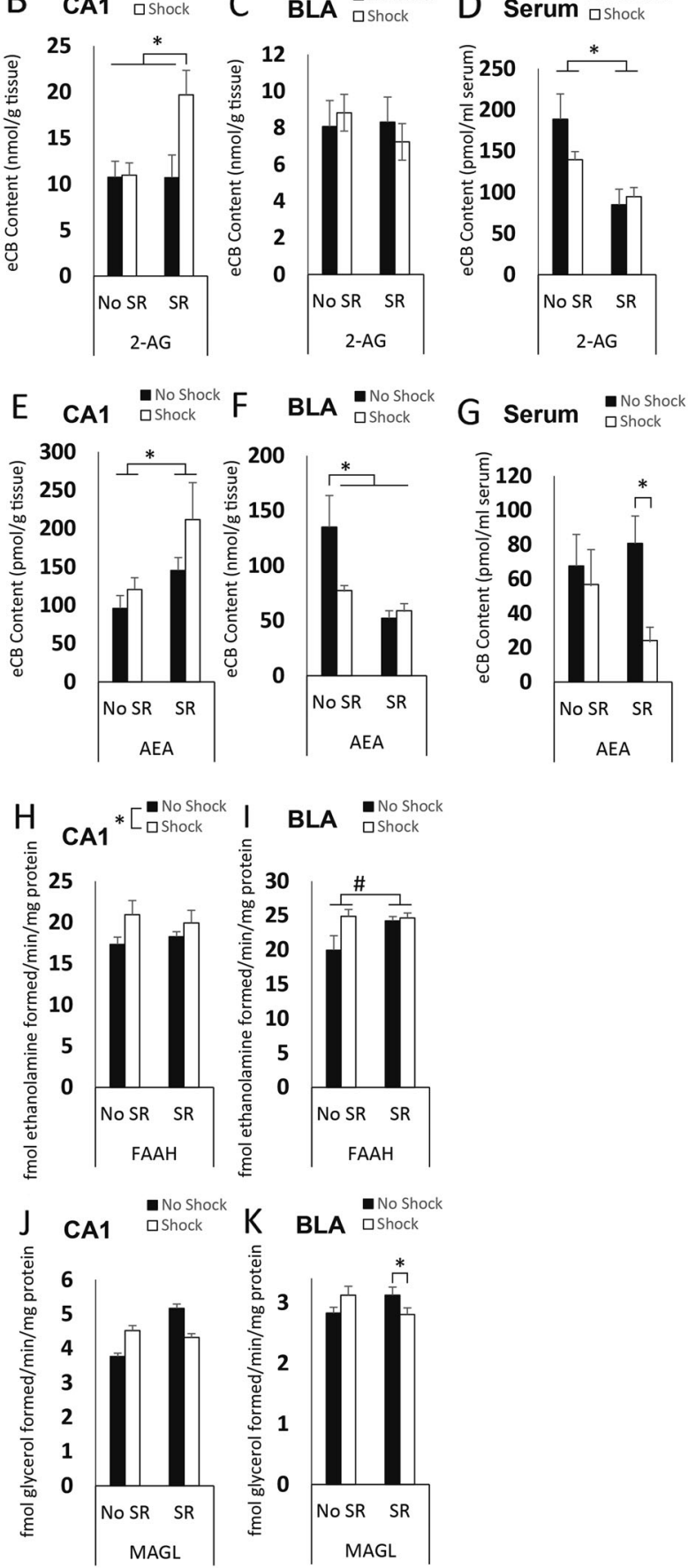

Fig. 5 The effects of exposure to shock and SRs on endocannabinoid content and hydrolytic enzyme activity. a A diagram illustrating the experimental design. Rats were exposed to shock on day 1 and to SR on days 3 and 5. Hundred minutes after SR exposure on day 5, rats were decapitated (i.e., overlapping the time in which HFS was delivered). $\mathbf{b}$ In the CA1, the Shock-SR group demonstrated increased 2-AG levels compared to the other groups $\left({ }^{*} p<0.05\right)$. c In the BLA, no significant effects for 2-AG were found. d In serum, exposure to SRs decreased 2-AG content $\left({ }^{*} p<0.05\right)$. e In the $C A 1$, exposure to SRs increased AEA content $\left({ }^{*} p<0.05\right)$. $f$ In the BLA, exposure to shock and/or SRs decreased AEA content ( $p<0.05)$. g In serum, the Shock-SR group demonstrated decreased AEA levels compared with the No shock-SR group $\left({ }^{*} p<0.05\right)$. h In the CA1, exposure to Shock increased FAAH activity $\left({ }^{*} p<0.05\right)$. i In the BLA, exposure to SRs increased FAAH activity $\left({ }^{\#} p=0.051\right)$. $j$ In the $C A 1$, no significant effects for MAGL activity were found. $\mathbf{k}$ In the BLA, the Shock-SR group demonstrated decreased MAGL activity compared with the Shock-No SR group ( $\left.{ }^{*} p<0.05\right)$

Experiment 5: the effects of exposure to trauma and reminders on endocannabinoid content and hydrolytic enzyme activities in the hippocampus and amygdala

We examined eCB content following exposure to shock and SRs (see Fig. 5a for study design). We used two-way ANOVA [(Shock $\times$ SR $(2 \times 2 \times 2)]$ on eCB content in the CA1, BLA, and serum.

In the CA1, significant effects were found of shock $\left(F_{(1,36)}=\right.$ $4.768, p<0.05)$, SRs $\left(F_{(1,36)}=4.193, p<0.05\right)$ and interaction $\left(F_{(1,36)}=4.309, p<0.05\right)$ on 2-AG content (Fig. 5b). Post hoc revealed a significant difference between the Shock-SR and the other groups $(p<0.05)$.

In the BLA, no significant effects for 2-AG were found of shock, SR or interaction (Fig. 5c).

In serum, a significant effect of SR $\left(F_{(1,36)}=14.447, p<0.001\right)$ on 2-AG content was found suggesting that exposure to SRs decreased 2-AG content (Fig. 5d).

In the CA1, AEA content analysis revealed a significant effect of $\operatorname{SR}\left(F_{(1,36)}=6.393, p<0.05\right)$, with no effect of shock or interaction, indicating that exposure to SR increased AEA content (Fig. 5e).

In the BLA, AEA content revealed a significant effect of SR $\left(F_{(1,36)}=11.064, p<0.01\right)$ and interaction $\left(F_{(1,36)}=4.501, p<0.05\right)$ with no effect of shock (Fig. $5 f$ ). Post hoc revealed a significant difference between the No shock-No SR group and the other groups $(p<0.05)$.

In serum, AEA content revealed a significant interaction $\left(F_{(1,36)}=4.199, p<0.05\right)$ with no effect of shock) or SR. Post hoc tests revealed a significant difference between the Shock-SR and No Shock-SR group ( $p<0.05$; Fig. $5 g$ ).

In a different set of rats, eCB enzyme assays were performed following exposure to shock and SRs (see Fig. 5a for study design). We used two-way ANOVA [(Shock $\times$ SR $(2 \times 2)]$ on FAAH and MAGL activity in the CA1 and BLA.

In the CA1, significant effect of shock $\left(F_{1,28)}=4.229, p<0.05\right)$ was found with no effect of SR or interaction on FAAH activity (Fig. 5h).

In the BLA, a significant effect of SR $\left(F_{(1,37)}=4.043, p=0.05\right)$ was found with no effect of Shock or interaction (Fig. 5i).

In the CA1, no significant effects were found on MAGL activity (Fig. 5j).

In the BLA, a significant interaction was found $\left(F_{(1,36)}=6.243\right.$, $p<0.05)$ with no effect of Shock or SR. Post hoc revealed a significant difference between the Shock-SR and Shock-No SR group ( $p<0.05$ ) (Fig. 5k).

When rats were decapitated $24 \mathrm{~h}$ after exposure to SR, no differences were observed in eCB content or activity (data not shown). 
Role of endocannabinoids in the hippocampus and amygdala in emotional... A Segev et al.

\section{DISCUSSION}

The main findings of this study are that URB597 administered systemically or into the CA1 or BLA prior to extinction attenuated fear and this effect persisted throughout extinction training and did not recuperate during spontaneous recovery (see Table 1). URB597 attenuated fear when administered before extinction, regardless if it was paired (immediately after SR2) or unpaired (24 $\mathrm{h}$ after SR2) with exposure to the reminder (i.e., reactivation of the memory trace). This suggests that extinction, rather than reconsolidation, is the predominant process in the fear attenuating effects of URB597 observed here.

Exposure to shock and reminders induced behavioral metaplasticity (impaired CA1-LTP and enhanced BLA-LTP) (see Table 2). Systemic administration of URB597 immediately or $24 \mathrm{~h}$ after the second SR prevented the shock/SR-induced impairment in CA1LTP and the enhancement in BLA-LTP. This metaplasticity modulation by URB597 is further supported by the differential effects of URB on plasticity in nonstressed rats; rats administered with URB, with no previous exposure to shock and reminders, demonstrated impaired CA1-LTP, but not BLA.

When measuring eCB content after SR, exposure to shock and SRs increased 2-AG and AEA levels in the CA1 and reduced AEA serum and BLA levels. When eCB catabolic enzyme activity was measured, exposure to shock (with or without exposure to SRs) increased FAAH activity in the CA1 and BLA. In the BLA, MAGL activity was reduced in rats exposed to shock and SRs compared to the No shock-SR group.

Taken together, the results suggest that exposure to shock and reminders induced alterations in eCB content and activity that could affect BLA-CA1 function to promote an enhanced fear response and that URB597 administered to stressed rats before extinction abolishes the fear response, perhaps by affecting metaplasticity in the BLA-CA1 circuit. This is supported by the fact that both the impairment (CA1) and enhancement (BLA) in LTP levels are normalized with URB; hence, the effect of URB is not to erase but to modulate fear-related memory.

Fear retrieval and extinction

URB597 abolished (BLA) or attenuated (CA1, systemic) fear and that these effects were CB1r- dependent. Similarly, AM404, an inhibitor of eCB breakdown and reuptake, and the FAAH inhibitor M3506 enhanced extinction and decreased shock-induced reinstatement of fear $[26,27]$. Also, URB597 $(0.1 \mathrm{mg} / \mathrm{kg})$ was found to enhance extinction consolidation and to restore normal social behavior in traumatized rats [28].

In the BLA, URB597 decreased latency levels to baseline, which could suggest that URB597 abolished the fear response, but we cannot rule out the possibility of other non-specific effects such as

\begin{tabular}{|c|c|c|}
\hline Figure \# & Protocol & Effect of URB597 \\
\hline $\begin{array}{l}\text { 1B- i.p. injection } \\
\text { 2B- intra-CA1 } \\
\text { 2C-intra-BLA }\end{array}$ & $\mathrm{SR} 2 \stackrel{5 \min }{\longrightarrow}$ URB $\stackrel{1 \mathrm{~h}}{\longrightarrow}$ Extinction & No fear \\
\hline $\begin{array}{l}\text { 1d- i.p. injection } \\
\text { S2B- intra-CA1 } \\
\text { S2C-intra-BLA }\end{array}$ & $\mathrm{SR} 2 \stackrel{24 \mathrm{~h}}{\longrightarrow}$ URB $\stackrel{1 \mathrm{~h}}{\longrightarrow}$ Extinction & No fear \\
\hline $\begin{array}{l}\text { S1B- i.p. injection } \\
\text { ( } 24 \mathrm{~h} \text { group) }\end{array}$ & $\mathrm{SR} 2 \stackrel{5 \mathrm{~min}}{\longrightarrow}$ URB $\stackrel{24 \mathrm{~h}}{\longrightarrow}$ Extinction & Extinction facilitated \\
\hline $\begin{array}{l}\text { S1B- i.p. injection } \\
\text { ( } 48 \mathrm{~h} \text { group) }\end{array}$ & $\mathrm{SR} 2 \stackrel{24 \mathrm{~h}}{\longrightarrow}$ URB $\stackrel{24 \mathrm{~h}}{\longrightarrow}$ Extinction & No effect \\
\hline \multicolumn{3}{|c|}{$\begin{array}{l}\text { The table summarizes the effects of URB597 on fear retrieval and extinction } \\
\text { in stressed rats. When URB597 was paired with SR or injected } 1 \mathrm{~h} \text { before } \\
\text { fear retrieval it facilitated extinction. BLA basolateral amygdala; SR } \\
\text { situational reminder; URB URB597). }\end{array}$} \\
\hline
\end{tabular}

Table 2. Summary of electrophysiological results

\begin{tabular}{lll}
\hline Figure \# & Protocol & Effect of URB597 \\
\hline $3 \mathrm{~F}, 4 \mathrm{~F}$ & $\mathrm{SR2} \stackrel{30 \mathrm{~min}}{\longrightarrow}$ URB $\stackrel{\text { 1h }}{\longrightarrow}$ HFS & LTP intact \\
S3B, 4S4B & SR2 $\stackrel{24 \mathrm{~h}}{\longrightarrow}$ URB $\stackrel{\text { hh }}{\longrightarrow}$ HFS & LTP intact \\
\hline
\end{tabular}

The table summarizes the effects of URB597 on LTP in stressed rats. When URB597 was injected $1 \mathrm{~h}$ before HFS, LTP levels were intact. HFS highfrequency stimulation; SR situational reminder; URB URB597).

a state dependent effect of the drug on performance. Yet, in the following days there was no recovery of the fear response.

We demonstarted the critical role of the eCB system in the BLA and CA1 in these poststress effects here and in previous studies $[6,13]$. However, as we have previousely shown, other brain regions may be critically involved (i.e., PFC, NAc, and insular cortex; see: [29-31]). Specifically, we have recently found that intra-NAc administration of WIN55,212-2 (5 $\mu \mathrm{g} / \mathrm{side}$ ) facilitated fear extinction in the shock and reminders model for PTSD [29]. Furthermore, although beyond the scope of the current paper, future work should also examine whether cannabinoid agents administered into the PFC prior to fear retrieval, would facilitate extinction.

\section{Plasticity}

Exposure to shock and reminders induced behavioral metaplasticity supporting our previous study [6]. Impaired hippocampal plasticity may relate to the impairment in general declarative memory function and in explicit information about the trauma [32]. Increased BLA activation/plasticity is associated with fearrelated symptoms in PTSD patients and heightened emotionality in rodents $[33,34]$.

The eCB system modulates the activation and sensitivity of the hypothalamic-pituitary-adrenal (HPA) axis [35]. Specifically, disrupting eCB signaling increases the activity of the HPA axis [36], whereas enhancement of eCB signaling inhibits the stress response by attenuating stress-induced HPA-axis activity (for review see [37]). Cannabinoid agonists administered following stress reduce the stress-induced activation of the HPA axis, such as corticosterone secretion [36, 38, 39].

The release of glucocorticoids following stress was found to impair hippocampal plasticity [40]. The hippocampus is sensitive to stress-related atrophy resulting from the stress hormone cortisol acting on glucocorticoid receptors (GRs)[41], and GR activation in the hippocampus was shown to activate eCB synthesis and inhibit GABA release [42].

The CA1/subiculum projection to the amygdala is NMDAdependent [43]. Glucocorticoids released following stress induce changes in glutamate neurotransmission in the hippocampus and amygdala, thereby influencing some aspects of cognitive and emotional processing [44]. It seems that exposure to severe stress may tilt the balance in favor of greater excitation in the BLA (i.e., greater NMDA receptor-mediated synaptic responses and reduced GABAergic inhibitory tone), which may render the BLA hyperresponsive to subsequent emotional experiences.

The anxiolytic effects of FAAH inhibitors are thought to derive from CB1-mediated suppression of glutamatergic versus GABAergic signaling [4]. It has been shown that CB1 deletion on glutamatergic terminals reversed the anxiolytic effects produced by low-dose administration of a CB1 agonist, while CB1 deletion on GABA forebrain neurons did not [45]. Moreover, FAAH inhibition was found to attenuate the stress-induced increase in amygdalar glutamatergic transmission [46]. The central amygdala has an excitatory role in HPA-axis activity and plays an integral role in the expression of fear responses. ECB signaling suppresses afferent glutamatergic transmission onto central amygdala neurons, which could represent an important synaptic mechanism regulating stress response 
physiology and anxiety-like behaviors; indeed, FAAH inhibition caused a CB1-dependent synaptic depression of glutamatergic transmission [47]. Inhibition of glutamatergic drive to locally targeting somatostatin-expressing GABAergic neurons would disinhibit central amygdala projection neurons and, in turn, inhibit central amygdala activity, thereby reducing anxiety and fear responses. Thus, enhancing cannabinoid signaling may attenuate the stress-induced elevations in glutamatergic transmission, which will reduce anxiety-like effects. Others have suggested that CB1 activation in the BLA enables the effects of glucocorticoids on the consolidation of aversive memory [48].

When AM251 was injected systemically to naïve rats, LTP was impaired in both CA1 and BLA. In the CA1, there was probably a floor effect (i.e., LTP levels were already impaired in the shock/SR group). When URB597 was injected systemically to naive rats, LTP was attenuated in the CA1 and intact in the BLA. This corroborates a previous study demonstrating that the effects of cannabinoid agonists on plasticity and behavior are different when administered alone or with stress exposure [49]. In the BLA, AM251 did not block the effects of URB597 on LTP in stressed rats, suggesting that URB597 effects on BLA-LTP after stress are not mediated via CB1 receptor, but via other receptors (e.g., TRPV1).

\section{ECB content and activity}

We have previously shown that exposure to shock and reminders upregulated $\mathrm{CB} 1 \mathrm{r}$ in the BLA and CA1 [6]. As URB increases AEA levels by inhibiting $F A A H$, we aimed to examine whether exposure to shock and reminders also affects eCB content and activity in the BLA and CA1. Kathuria et al. [10] have shown a significant reduction in FAAH activity $25 \mathrm{~min}-6 \mathrm{~h}$ after a single injection of URB $(0.3 \mathrm{mg} / \mathrm{kg})$. As rats exposed to trauma and reminders demonstrate a deficiency in AEA levels, this might provide support to the stresspreventing effects of URB597, that increases AEA availability.

Exposure to the second SR enhanced 2-AG levels in the hippocampus of rats exposed to shock, in agreement with other findings demonstrating that stress increases 2-AG content, perhaps as a result of increased central nervous system glucocorticoid receptor activation [42]. MAGL activity was unchanged in the CA1, which is consistent with increased synthesis as a results of GR activation. There was no effect on 2-AG content in the BLA, supporting studies showing a relative insensitivity of BLA 2-AG content to stress exposure [50]. Interestingly, however, shock exposure itself decreased MAGL activity in the BLA, but this change did not impact total 2-AG tissue contents. It is possible that synaptic 2-AG is increased in response to shock exposure. Serum 2-AG levels were reduced in rats exposed to shock, SRs or both, compared to the no shock-no SR (i.e., control) group. This finding is interesting in light of data that circulating 2-AG concentrations in humans with PTSD are reduced compared to those without [51, 52].

These data corroborate previous finding that $30 \mathrm{~min}$ exposure to restraint stress in rats produced an increase in hippocampal 2AG content [42], but not within the amygdala [50]. Although in another PTSD model, predator threat triggered long-term changes in amygdala 2-AG levels [53]. It has been suggested that 2-AG elevation following stress may contribute to the termination of the stress response by affecting glucocorticoid-mediated negative feedback habituation to repeated exposure to homotypic stressors $[36,54]$.

Exposure to the second SR increased AEA levels in the CA1 and decreased serum and BLA AEA levels in rats exposed to shock. Several studies suggest that reduced AEA-BLA levels may result from an increase in corticotropin-releasing factor)CRF) signaling $[39,46,50,54,55]$. CRF, acting through CRF receptor 1 (CRFR1), elevated AEA as a result as a transient inhibition of FAAH activity in the BLA [55]. Shock and SR reduced FAAH activity, which is consistent with this hypothesis. On the other hand, AEA contents in the amygdala and hippocampus are increased following glucocorticoid administration in the absence of stress [56]. Thus, it appears that AEA contents can be altered in both directions following stress.

In general, it has been suggested that there is a deficiency in eCB content (and in particular AEA) in PTSD patients that could explain the therapeutic value in using cannabinoid agonists [15]. Specifically, FAAH inhibition was found to increase brain AEA levels and to diminish anxiety-like responses following stress $[27,57]$. Within the BLA, stress increased FAAH activity and decreased AEA content were found [58]. It has been shown that intra-BLA FAAH inhibitor attenuated activation of the HPA axis in response to stress, suggesting that a reduction of AEA tone within the BLA contributes to activation of the HPA axis [58]. In our study, the pattern of changes in AEA and 2-AG serum content is opposite to the pattern of changes in the CA1; this suggests that AEA and 2AG concentrations in the serum are stress-sensitive but could be coming from a different source.

\section{Summary}

Targeting the eCB system before extinction may be beneficial in fear memory attenuation and may have a translational value in facilitating exposure therapy.

\section{FUNDING}

This research was supported by The Binational Science Foundation (BSF) [Grant no. 2011/256 to I.A. and C.J.H. (URL: www.bsf.org.il/)] and by the Research and Education Component of the Advancing a Healthier Wisconsin Endowment at the Medical College of Wisconsin.

\section{ADDITIONAL INFORMATION}

Supplementary Information accompanies this paper at (https://doi.org/10.1038/ s41386-018-0135-4).

Competing interests: The authors declare no competing interests.

Publisher's note: Springer Nature remains neutral with regard to jurisdictional claims in published maps and institutional affiliations.

\section{REFERENCES}

1. Guthrie RM, Bryant RA. Extinction learning before trauma and subsequent posttraumatic stress. Psychosom Med. 2006;68:307-11.

2. Ganon-Elazar E, Akirav I. Cannabinoids prevent the development of behavioral and endocrine alterations in a rat model of intense stress. Neuropsychopharmacology. 2012;37:456-66.

3. Hillard CJ. Stress regulates endocannabinoid-CB1 receptor signaling. Semin Immunol. 2014;26:380-8.

4. Lutz B, Marsicano G, Maldonado R, Hillard CJ. The endocannabinoid system in guarding against fear, anxiety and stress. Nat Rev Neurosci. 2015; 16:705-18.

5. Moreira FA, Wotjak CT. Cannabinoids and anxiety. Behav Neurobiol Anxiety Treat. 2010;2:429-50.

6. Shoshan N, Segev A, Abush H, Mizrachi Zer-Aviv T, Akirav I. Cannabinoids prevent the differential long-term effects of exposure to severe stress on hippocampaland amygdala-dependent memory and plasticity. Hippocampus. 2017;27:1093-109.

7. Korem N, Akirav I. Cannabinoids prevent the effects of a footshock followed by situational reminders on emotional processing. Neuropsychopharmacology. 2014:39:2709-22.

8. Haller J, Goldberg SR, Pelczer KG, Aliczki M, Panlilio LV. The effects of anandamide signaling enhanced by the FAAH inhibitor URB597 on coping styles in rats. Psychopharmacol (Berl). 2013;230:353-62.

9. Adamczyk P, Golda A, McCreary AC, Filip M, Przegaliriski E. Activation of endocannabinoid transmission induces antidepressant-like effects in rats. Acta Physiol Pol. 2008;59:217.

10. Kathuria S, Gaetani S, Fegley D, Valiño F, Duranti A, Tontini A et al. Modulation of anxiety through blockade of anandamide hydrolysis. Nat Med. 2003;9:76-81.

11. Aliczki M, Barna I, Till I, Baranyi M, Sperlagh B, Goldberg SR et al. The effects anandamide signaling in the prelimbic cortex and basolateral amygdala on coping with environmental stimuli in rats. Psychopharmacology. 2016;233:1889-99. 
12. Burstein O, Shoshan N, Doron R, Akirav I. Cannabinoids prevent depressive-like symptoms and alterations in BDNF expression in a rat model of PTSD. Prog Neuropsychopharmacol Biol Psychiatry. 2018;84:129-39.

13. Aisenberg N, Serova L, Sabban EL, Akirav I. The effects of enhancing endocannabinoid signaling and blocking corticotrophin releasing factor receptor in the amygdala and hippocampus on the consolidation of a stressful event. Eur Neuropsychopharmacol. 2017;27:913-27.

14. Morena M, Leitl KD, Vecchiarelli HA, Gray JM, Campolongo P, Hill MN. Emotional arousal state influences the ability of amygdalar endocannabinoid signaling to modulate anxiety. Neuropharmacology. 2016;111:59-69.

15. Neumeister A. The endocannabinoid system provides an avenue for evidencebased treatment development for PTSD. Depress Anxiety. 2013;30:93-6.

16. Nader K, Schafe GE, Le Doux JE. Fear memories require protein synthesis in the amygdala for reconsolidation after retrieval. Nature. 2000;406:722.

17. Abraham WC, Bear MF. Metaplasticity: the plasticity of synaptic plasticity. Trends Neurosci. 1996;19:126-30.

18. Schmidt MV, Abraham WC, Maroun M, Stork O, Richter-Levin G. Stress-induced metaplasticity: from synapses to behavior. Neuroscience. 2013;250:112-20.

19. Abraham WC, Tate WP. Metaplasticity: a new vista across the field of synaptic plasticity. Prog Neurobiol. 1997;52:303-23.

20. Kim JJ, Yoon KS. Stress: metaplastic effects in the hippocampus. Trends Neurosci. 1998;21:505-9.

21. Mizrachi Zer-Aviv T, Akirav I. Sex differences in hippocampal response to endocannabinoids after exposure to severe stress. Hippocampus. 2016;26:947-57.

22. Arenos JD, Musty RE, Bucci DJ. Blockade of cannabinoid CB1 receptors alters contextual learning and memory. Eur J Pharmacol. 2006;539:177-83.

23. Rodríguez-Cueto C, Hernández-Gálvez M, Hillard CJ, Maciel P, García-García L, Valdeolivas $\mathrm{S}$, et al. Dysregulation of the endocannabinoid signaling system in the cerebellum and brainstem in a transgenic mouse model of spinocerebellar ataxia type-3. Neuroscience. 2016;339:191-209.

24. Spagnolo PA, Ramchandani VA, Schwandt ML, Kwako LE, George DT, Mayo LM, et al. FAAH gene variation moderates stress response and symptom severity in patients with posttraumatic stress disorder and comorbid alcohol dependence. Alcohol Clin Exp Res. 2016;40:2426-34.

25. Dean C, Hillard CJ, Seagard JL, Hopp FA, Hogan QH. Components of the cannabinoid system in the dorsal periaqueductal gray are related to resting heart rate. Am J Physiol Regul Integr Comp Physiol. 2016;311:R254-62.

26. Chhatwal JP, Davis M, Maguschak KA, Ressler KJ. Enhancing cannabinoid neurotransmission augments the extinction of conditioned fear. Neuropsychopharmacology. 2005;30:516-24.

27. Gunduz-Cinar O, Hill MN, McEwen BS, Holmes A. Amygdala FAAH and anandamide: mediating protection and recovery from stress. Trends Pharmacol Sci. 2013;34:637-44.

28. Morena M, Berardi A, Colucci P, Palmery M, Trezza V, Hill MN et al. Enhancing endocannabinoid neurotransmission augments the efficacy of extinction training and ameliorates traumatic stress-induced behavioral alterations in rats. Neuropsychopharmacology. 2018;43:1284-96.

29. Korem N, Lange R, Hillard CJ, Akirav I. Role of beta-catenin and endocannabinoids in the nucleus accumbens in extinction in rats exposed to shock and reminders. Neuroscience. 2017;357:285-94.

30. Levin N, Kritman M, Maroun M, Akirav I. Differential roles of the infralimbic and prelimbic areas of the prefrontal cortex in reconsolidation of a traumatic memory. Eur Neuropsychopharmacol. 2017;27:900-12.

31. Zubedat S, Akirav I. The involvement of cannabinoids and mTOR in the reconsolidation of an emotional memory in the hippocampal-amygdala-insular circuit. Eur Neuropsychopharmacol. 2017;27:336-49.

32. Elzinga BM, Bremner JD. Are the neural substrates of memory the final common pathway in posttraumatic stress disorder (PTSD)? J Affect Disord. 2002;70:1-17.

33. Garcia R, Paquereau J, Vouimba RM, Jaffard R. Footshock stress but not contextual fear conditioning induces long-term enhancement of auditory-evoked potentials in the basolateral amygdala of the freely behaving rat. Eur J Neurosci. 1998;10:457-63.

34. Shin LM, Liberzon I. The neurocircuitry of fear, stress, and anxiety disorders. Neuropsychopharmacology. 2010;35:169-91.

35. Hillard CJ, Beatka M, Sarvaideo J. Endocannabinoid signaling and the hypothalamic-pituitary-adrenal axis. Compr Physiol. 2016;7:1-15.

36. Patel S,Roelke CT,Rademacher DJ,Cullinan WE,Hillard CJ, Endocannabinoid signaling negatively modulates stress-induced activation of the hypothalamicpituitary-adrenal axis. Endocrinology. 2004;145:5431-8.
37. Akirav I. Cannabinoids and glucocorticoids modulate emotional memory after stress. Neurosci Biobehav Rev. 2013;37:2554-63.

38. Ganon-Elazar E, Akirav I. Cannabinoid receptor activation in the basolateral amygdala blocks the effects of stress on the conditioning and extinction of inhibitory avoidance. J Neurosci. 2009;29:11078-88.

39. Hill MN,McLaughlin RJ,Morrish AC,Viau V,Floresco SB,Hillard CJ, et al. Suppression of amygdalar endocannabinoid signaling by stress contributes to activation of the hypothalamic-pituitary-adrenal axis. Neuropsychopharmacology. 2009;34:2733-45.

40. Kim JJ, Diamond DM. The stressed hippocampus, synaptic plasticity and lost memories. Nat Rev Neurosci. 2002;3:453-62.

41. Watanabe $Y$, Saito $H$, Abe K. Effects of glycine and structurally related amino acids on generation of long-term potentiation in rat hippocampal slices. Eur J Pharmacol. 1992;223:179-84.

42. Wang M, Hill MN, Zhang L, Gorzalka BB, Hillard CJ, Alger BE. Acute restraint stress enhances hippocampal endocannabinoid function via glucocorticoid receptor activation. J Psychopharmacol (Oxf). 2011;26:56-70.

43. Maren S, Fanselow MS. Synaptic plasticity in the basolateral amygdala induced by hippocampal formation stimulation in vivo. J Neurosci. 1995;15:7548-64.

44. Popoli M, Yan Z, McEwen BS, Sanacora G. The stressed synapse: the impact of stress and glucocorticoids on glutamate transmission. Nat Rev Neurosci. 2012;13:22-37.

45. Rey $A A$, Purrio $M$, Viveros $M-P$, Lutz $B$. Biphasic effects of cannabinoids in anxiety responses: $\mathrm{CB} 1$ and $\mathrm{GABAB}$ receptors in the balance of GABAergic and glutamatergic neurotransmission. Neuropsychopharmacology. 2012;37:2624-34.

46. Natividad LA, Buczynski MW, Herman MA, Kirson D, Oleata CS, Irimia C, et al. Constitutive increases in amygdalar corticotropin-releasing factor and fatty acid amide hydrolase drive an anxious phenotype. Biol Psychiatry. 2017;82:500-10.

47. Ramikie TS, Nyilas R, Bluett RJ, Gamble-George JC, Hartley ND, Mackie K, et al. Multiple mechanistically distinct modes of endocannabinoid mobilization at central amygdala glutamatergic synapses. Neuron. 2014;81:1111-25.

48. Campolongo P, Roozendaal B, Trezza V, Hauer D, Schelling G, McGaugh JL et al. Endocannabinoids in the rat basolateral amygdala enhance memory consolidation and enable glucocorticoid modulation of memory. Proc Natl Acad Sci USA 2009;106:4888-93.

49. Abush H, Akirav I. Cannabinoids ameliorate impairments induced by chronic stress to synaptic plasticity and short-term memory. Neuropsychopharmacology. 2013;38:1521-34.

50. Rademacher DJ, Meier SE, Shi L, Vanessa Ho W-S, Jarrahian A, Hillard CJ. Effects of acute and repeated restraint stress on endocannabinoid content in the amygdala, ventral striatum, and medial prefrontal cortex in mice. Neuropharmacology. 2008;54:108-16.

51. Hill MN,Bierer LM,Makotkine I,Golier JA,Galea S,McEwen BS, et al. Reductions in circulating endocannabinoid levels in individuals with posttraumatic stress disorder following exposure to the World Trade Center attacks. Psychoneuroendocrinology. 2013;38:2952-61.

52. Schaefer C, Enning F, Mueller JK, Bumb JM, Rohleder C, Odorfer TM, et al. Fatty acid ethanolamide levels are altered in borderline personality and complex posttraumatic stress disorders. Eur Arch Psychiatry Clin Neurosci. 2014;264:459-63.

53. Lim J, Igarashi M, Jung K-M, Butini S, Campiani G, Piomelli D. Endocannabinoid modulation of predator stress-induced long-term anxiety in rats. Neuropsychopharmacology. 2016:41:1329-39.

54. Hill MN,McLaughlin RJ,Bingham B,Shrestha L,Lee TT,Gray JM, et al. Endogenous cannabinoid signaling is essential for stress adaptation. Proc Natl Acad Sci. 2010;107:9406-11.

55. Gray JM, Vecchiarelli HA, Morena M, Lee $\Pi$, Hermanson DJ, Kim AB, et al. Corticotropin-releasing hormone drives anandamide hydrolysis in the amygdala to promote anxiety. J Neurosci. 2015;35:3879-92.

56. Hill MN,Karatsoreos IN,Hillard CJ,McEwen BS, Rapid elevations in limbic endocannabinoid content by glucocorticoid hormones in vivo. Psychoneuroendocrinology. 2010;35:1333-8.

57. Bluett RJ,Gamble-George JC,Hermanson DJ,Hartley ND,Marnett LJ,Patel S, Central anandamide deficiency predicts stress-induced anxiety: behavioral reversal through endocannabinoid augmentation. Transl Psychiatry. 2014;4:e408

58. Hill MN,Miller GE,Carrier EJ,Gorzalka BB,Hillard CJ, Circulating endocannabinoids and $\mathrm{N}$-acyl ethanolamines are differentially regulated in major depression and following exposure to social stress. Psychoneuroendocrinology. 2009;34:1257-62. 